\title{
A Structural VAR Analysis of Electrical Energy Consumption and Real Gross Domestic Product: Evidence from Turkey
}

\author{
Sabri Azgun \\ Department of Economics, the Faculty of Economic and Administration Sciences, \\ Yuzuncu Yil University, Zeve Campüs, 65080, Van, Turkey \\ E-mail: sabriazgun@gmail.com
}

Received: March 15, 2011

Accepted: March 25, 2011

doi:10.5539/ijef.v3n5p161

\begin{abstract}
This paper examines the relationship between the aggregate electricity consumption, the sub-components of electricity consumption (industrial electricity consumption, residential and commercial, government offices and street illuminations) and real gross domestic product by means of a structural VAR model for the Turkish economy. The main purpose of the paper is to examine the impact of the aggregate electricity consumption innovations and the sub-components of electricity consumption innovations on real gross domestic product. The impact of real gross domestic product innovations on the aggregate electricity consumption and the sub-components of electricity energy consumption is also analyzed. Both the structural factorization results and impulse-response functions show that aggregate electricity consumption shocks and the sub-components shocks of electricity consumption has not fluctuate real gross domestic product, while real gross domestic product innovations affect the total electrical energy consumption and the sub-components of electricity consumption.
\end{abstract}

Keywords: Electricity Consumption, Real Gross Domestic Product, Structural VAR Model

\section{Introduction}

The two major oil crises of the 1970s revealed the importance of energy as a production factor. Energy is necessary to realize economic development and is one of the basic inputs. With economic development, the demand for energy increases, and economies have become dependent on energy. The energy dependence of the economies has pushed the search for renewable alternative energy sources. In the energy components, electricity not only is renewable energy, but is also a component of the highest quality energy. Over time, the share of electrical energy consumption has increased. Electricity is followed by natural gas, oil, coal and other fuels. In the Turkish economy, with economic development, the consumption of electricity has increased over time. From 1968 until 2008, while the economy grew $6.22 \%$ on average, in the same period, electricity consumption increased by $8.65 \%$.

The Turkish economy is dependent on the outside world in terms of energy to maintain its economic development. In the Turkish economy, a significant portion of petroleum, electricity, natural gas and coal needs have been met through imports. As a result, the Turkish economy has been confronted with constraints in terms of energy supply. For Turkey's economy to achieve sustainable economic growth, the demand for energy should be planned and the planned energy demand should be met. Thus, the energy supply and demand shocks will affect the growth path of real output. In Turkish economy, the electricity in types of energy is produced entirely of national resources. Therefore, electrical energy is of great importance in economic development.

The purpose of this study is to display the relationship between electrical energy consumption and gross domestic product by means of a structural VAR model. In this context, the study has been planned in five sections. The first section is the introduction of the study. In the second section, the conceptual framework and the related literature have been provided. In the third section, a structural VAR model to display the reaction of gross domestic product to energy innovations is introduced. In the fourth section, the analysis is presented. In the fifth and the final section, the conclusions are drawn.

\section{Conceptual Framework and Related Literature}

Since the 1970s, a number of studies have attempted to examine the causal relationship between energy consumption and economic growth in both developed and developing countries. Empirical findings on the direction of causality between energy consumption and economic growth are controversial. The empirical evidence of the previous studies on the issues shows that the causal relationship between energy consumption and economic growth differs from one economy to another and over time. Also, the relationship between energy consumption and economic growth may be linked to the preference of energy consumption variable. 
In the literature, the studies that have analysed the relationship between energy consumption and economic growth can be classified in three main groups. The first group of studies are made in the empirical causality context. These studies tried to identify the direction of the relationship between energy consumption and economic growth by means of various causality tests for a single country. To determine the direction of causality in the studies, they used the ADRL bound testing approach, standard Engle-granger causality, VAR causality and vector error correction causality tests. In the empirical causality context, the causal relationship between energy consumption and economic growth has important implications from theoretical, empirical and policy standpoints. In this way, the relationship between energy consumption and economic growth was explained by four basic testable hypotheses. The first is a growth hypothesis. The hypothesis asserted that energy consumption serves a vital role in economic growth; both a direct input in the production process and an indirect complement to labour and capital production factors. A unidirectional causal relationship from electricity consumption towards economic growth implies that economic growth is dependent on energy consumption. Thus, a decrease in energy consumption restrains economic growth. In the economy, which is energy dependent, the growth hypothesis suggests that an increase in energy consumption causes an increase in real GDP. On the other hand, an increase in energy consumption may have a negative effect on economic growth (Squalli, 2007). Such a possibility could result from excessive energy consumption, relatively unproductive sectors of the economy, capacity constraints, or inefficiencies in energy production. Empirical evidence from the studies which supported the growth hypothesis and focused on Turkey was produced by Altinay and Karagol (2005), and by Jobert and Karanfil (2007). Evidence for Fiji was produced by Narayan and Singh (2007), for Tanzania by Odhiambo (2009), for most of the OPEC countries by Squalli (2007), and for China by Shiu and Lam (2004).

The second hypothesis is the conservation hypothesis. This hypothesis suggests that energy conservation policies designed to reduce energy consumption and waste may not have an adverse impact on real GDP. In this context, a unidirectional causal relationship from economic growth to energy consumption implies that a country is not entirely dependent on energy for its economic growth. And the energy conservation policies can be implemented with little or no adverse effects on economic growth. The conservation hypothesis is confirmed if an increase in real GDP causes an increase in energy consumption. On the other hand, it is argued that a growing economy which is constrained by political influences, infrastructure, or mismanagement of resources, may generate inefficiencies along with a reduction in the consumption of goods and services including energy (Squalli, 2007). The empirical studies carried out by Mazumder and Marathe (2007) for Bangladesh, by Gosh (2002) for India, by Hatemi-J and Irandoust (2005) for Sweden, by Hondroyiannis, Sarantis and Papapetrou (2002) for Greece, by Cheng and Lai (1997) for Taiwan, and by Abosedra and Baghestani (1989) for the United States, were all consistent with the conservation hypothesis.

The third hypothesis is the neutrality hypothesis. The testable hypothesis presumes that energy consumption is a small component of the economy's output and thus may have little or no effect on economic growth. As in the case of the conservation hypothesis, energy conservation policies would not have an adverse effect on economic growth. The neutrality hypothesis is supported by the presence of no causal relationship between energy consumption and real GDP. The empirical studies carried out by Cheng (1997) for Mexico and Venezuela, except Brazil, were consistent with the neutrality hypothesis.

The fourth hypothesis is the feedback hypothesis. According to the hypothesis, energy consumption and real GDP are interrelated and may very well serve to complement each other. The presence of bidirectional causality between energy consumption and real GDP supports the feedback hypothesis, whereby an energy policy oriented toward improvements in energy consumption efficiency may not have an adverse effect on economic growth. The empirical studies by Yang (2000) for Taiwan, and Paul and Bhattacharya (2004) for India supported the feedback hypothesis.

The second group of studies relied on cross-sectional analysis, which generalizes the causal relationship between energy consumption and economic growth across an economy. The question of using the cross-sectional analysis method is that gathering into group economies that are at different stages of economic upswing. This method fails to address the country-specific effects of energy consumption on economic growth. However, the basic purpose of these kinds of studies regarding the relationship between energy consumption and economic growth is to set a general truth (for instance, see Odhiambo, 2008; Narayan \& Smyth, 2008; Aperdis \& Payne, 2009).

The third group of studies is based on the SVAR model. In the energy economics literature, there are quite a few studies based on the SVAR model. The studies carried out in the structural VAR model context have put forth the reaction of gross domestic product to energy innovations (for instance, Narayan et al., 2008).

\section{Model}

The main purpose of structural VAR (SVAR) estimation is to obtain non recursive orthogonalization of the error terms for impulse-response analysis. This alternative to recursive Cholesky orthogonalization requires the user to 
impose enough restrictions to identify the orthogonal (structural) components of the error terms. The structural VAR constitutes the impulse-response relationship between energy consumption and real GDP for Turkey. In the structural VAR context, the bi-variable system of equations can be written as follows:

$$
\begin{gathered}
G D P_{t}=a_{10}-a_{12} A E C_{t t}+a_{11 *}^{*} G D P_{t-1}+a_{12}^{*} A E C_{t-1}+b_{11} \varepsilon_{t}^{G D P}+b_{12} \varepsilon_{t}^{A E C} \\
A E C_{t}=a_{20}-a_{22} G D P_{t t}+a_{21 *}^{*} G D P_{t-1}+a_{22}^{*} A E C_{t-1}+b_{21} \varepsilon_{t}^{G D P}+b_{22} \varepsilon_{t}^{A E C}
\end{gathered}
$$

Where it is assumed that (i) both $G D P_{t}$ and $A E C_{t}$ variables are stationary; (ii) $\varepsilon_{t}^{G D P}$ and $\varepsilon_{t}^{A E C}$ are white-noise disturbances with standard deviations of $\sigma_{G D P}$ and $\sigma_{A E C}$ respectively. In the equations system; and (iii) $\varepsilon_{t}^{G D P}$ and $\varepsilon_{t}^{A E C}$ are uncorrelated white-noise disturbances. Equations 1 and 2 constitute a first-order vector auto-regression (VAR) because the longest lag length is unity. The structure of the equations system incorporates feedback because $G D P_{t}$ and $A E C_{t}$ variables are allowed to affect each other. For example $-a_{12}$ is the contemporaneous effect of a unit change of $\quad$ on $G D P_{t}$ and $a_{12}^{*}$ is the effect of a unit change in $A E C_{t-1}$ on $G D P_{t}$. Note that the $\varepsilon_{t}^{G D P}$ and $\varepsilon_{t}^{A E C}$ are pure innovations (or shocks) in $G D P_{t}$ and $A E C_{t}$ variables, respectively. For instance, if parameter $a_{12}$ is equal to zero, $\varepsilon_{t}^{A E C}$ does not have a indirect contemporaneous effect on $G D P_{t}$. The equations set 1 are not reduced-form equations because any variable in the model (e.g. $G D P_{t}$ ) has a contemporaneous effect on the other variables (e.g. $I E C_{t}$ ), but it is possible to transform the system of equations into a more usable form. Using matrix algebra, the system can be written as follows:

$$
\left[\begin{array}{cc}
1 & a_{12} \\
a_{21} & 1
\end{array}\right]\left[\begin{array}{l}
G D P_{t} \\
A E C_{t}
\end{array}\right]=\left[\begin{array}{l}
a_{10} \\
a_{20}
\end{array}\right]+\left[\begin{array}{ll}
a_{11}^{*} & a_{12}^{*} \\
a_{21}^{*} & a_{22}
\end{array}\right]\left[\begin{array}{c}
G D P_{t-1} \\
E C_{t-1}
\end{array}\right]+\left[\begin{array}{ll}
b_{11} & b_{12} \\
b_{21} & b_{22}
\end{array}\right]\left[\begin{array}{l}
\varepsilon_{t}^{G D P} \\
\varepsilon_{t}^{A E C}
\end{array}\right]
$$

Or in a compact form:

$$
A x_{t}=A_{o}+A_{1}^{*} x_{t-1}+B \varepsilon_{t}
$$

Where matrix $A$ and $A^{*}$, respectively, are used to model current (contemporaneous) and the past relationship between the variables, while matrix $B$ contains the structural form parameters of the model. $\varepsilon_{t}$ is the vector of structural disturbances and $\operatorname{var}\left(\varepsilon_{t}\right)=\Lambda$, where $\Lambda$ is a diagonal matrix with the variance of structural disturbances making up the diagonal elements.

$A=\left[\begin{array}{cc}1 & a_{12} \\ a_{21} & 1\end{array}\right], \quad X_{t}=\left[\begin{array}{l}G D P_{t} \\ A E C_{t}\end{array}\right], \quad A_{O}=\left[\begin{array}{l}a_{10} \\ a_{20}\end{array}\right], \quad A_{1}^{*}=\left[\begin{array}{ll}a_{11}^{*} & a_{12}^{*} \\ a_{21}^{*} & a_{22}\end{array}\right], \quad B=\left[\begin{array}{ll}b_{11} & b_{12} \\ b_{21} & b_{22}\end{array}\right] \varepsilon_{t}=\left[\begin{array}{l}\varepsilon_{t}^{G D P} \\ \varepsilon_{t}^{A E C}\end{array}\right]$

Determining $\Psi_{0}=A^{-1} A_{0}, \quad \Psi_{1}=A^{-1} A_{1}^{*}$ and $\mu_{t}=A^{-1} B \varepsilon_{t} \quad$ yields the following equations system 4 and 5:

$$
\begin{gathered}
G D P_{t}=\Psi_{1 o}+\Psi_{11} G D P_{t-1}+\Psi_{12} A E C_{t-1}+\mu_{1 t} \\
A E C_{t}=\Psi_{2 o}+\Psi_{21} G D P_{t-1}+\Psi_{22} A E C_{t-1}+\mu_{2 t}
\end{gathered}
$$

Or compact form:

$$
x_{t}=\Psi_{0}+\Psi_{1}+\mu_{t}
$$

The problem is to take the observed values of $\mu_{t}$ and restrict the system so as to recover $\varepsilon_{t}$. It is common knowledge in this literature that shocks cannot be observed directly. This requires imposing some restrictions. The common practice is to multiply equation 3 by $A^{-1}$. So, the relationship between the reduced form disturbances and structural disturbances is as follows:

$$
\mu_{t}=A^{-1} B \varepsilon_{t}
$$

It can be estimated as the $A B$ model proposed Amisano and Giannini (1997). Alternatively, equation 7 is written as follows:

$$
A \mu_{t}=B \varepsilon_{t}
$$

Sims (1986) and Bernanke (1986) proposed a decomposition method that uses short run (i.e. contemporaneous) restrictions derived from theoretical models or widely accepted assumptions. In this context, to depict the 
relationship between aggregate electricity consumption and gross domestic product, the structural VAR has the following restrictions:

$$
\left[\begin{array}{l}
\varepsilon_{t}^{G D P} \\
\varepsilon_{t}^{A E C}
\end{array}\right]=\left[\begin{array}{cc}
1 & 0 \\
N A & 1
\end{array}\right]\left[\begin{array}{l}
\mu_{t}^{G D P} \\
\mu_{t}^{A E C}
\end{array}\right]
$$

Where, $\varepsilon_{t}^{G D P}$ and $\varepsilon_{t}^{A E C}$ are structural disturbances; in other words, electricity consumption shocks (innovations) and real GDP shocks (innovations), respectively. And the error terms $\mu_{t}^{G D P}$ and $\mu_{t}^{A E C}$ are residuals in the reduced form. In the constraints (9), the first equation depicts a non contemporaneous relationship between real GDP and aggregate electricity consumption. However, the second equation represents a contemporaneous response of real GDP to electricity consumption innovations. Similarly, in order to determine the relationship between sub-elements of electricity consumption and gross domestic product, a structural VAR model is defined as follows:

$$
\left[\begin{array}{c}
\varepsilon_{t}^{G D P} \\
\varepsilon_{t}^{I E C} \\
\varepsilon_{t}^{A U E C} \\
\varepsilon_{t}^{R C E C} \\
\varepsilon_{t}^{S L E C}
\end{array}\right]=\left[\begin{array}{ccccc}
1 & 0 & 0 & 0 & 0 \\
N A & 1 & 0 & 0 & 0 \\
N A & 0 & 1 & 0 & 0 \\
N A & 0 & 0 & 1 & 0 \\
N A & 0 & 0 & 0 & 1
\end{array}\right]\left[\begin{array}{c}
\mu_{t}^{G D P} \\
\mu_{t}^{I E C} \\
\mu_{t}^{A U E C} \\
\mu_{t}^{R C E C} \\
\mu_{t}^{S L E C}
\end{array}\right]
$$

In the constraints (10), IEC represents the industrial electricity consumption, $A U E C$ represents electricity consumption which is used in government offices, $R C E C$ represents the electric consumption used in commercial establishments and SLEC represents electricity consumption for street lighting.

In the constraints (10), the first equation depicts a non contemporaneous relationship between real GDP and sub-components of the electricity consumption. The second equation represents a contemporaneous response of industrial electricity consumption to real GDP innovations. The others equations, respectively, represent a contemporaneous response of government offices, residential and commercial, street illuminations electricity consumption to real GDP innovations. Any of the sub-elements of the electricity consumption does not give any response to a shock to any one sub-component of the electricy consumption.

\section{Analysis}

In this study, the relationship between aggregate electricity consumption, sub-components of the electricity energy consumption (industrial electricity consumption, government offices, residential and commercial, street illuminations) and gross domestic product have been investigated by means of a structural VAR model for the Turkish economy. The yearly data for the period between 1968 and 2008 have been used for the analysis. The data set has been arranged and prepared according to the information submitted by TurkStat (Turkish Statistical Institute).

All variables, which are expressed in logarithmic terms, have been used in their first differences. Gross domestic product is expressed with $G D P$; total electricity consumption is expressed with $A E C$; industrial electricity consumption is expressed with $I E C$; government offices are expressed with $A U E C$; residential and commercial are expressed with $R C E C$; and street illuminations are expressed with $S L E C$ notations. The structural relationship between the $A E C$ and $G D P$ series has been defined by constraints (9). Also, in the structural VAR context, the relationship between IEC, RCEC, AUEC, SLEC and GDP variables has been determined by constraints (10). The impulse response functions of the impact of gross domestic product shocks on the electricity consumptions, respectively, are plotted in Figures 1a-5a. Similarly, the impulse response functions of the effect of electricity consumption innovations on the gross domestic product, respectively, are plotted in Figures $1 \mathrm{~b}-5 \mathrm{~b}$. The lag lengths of the VAR model are selected using the Schwarz info criterion. For all variables, the optimal lag length is two.

Within the scope of the VAR system, the structural factorization of gross domestic product and aggregate electricity energy consumption is given Table 1. The impulse response functions of the impact of gross domestic product shocks on the aggregate electricity consumptions, respectively, are plotted in Figure 1a. Similarly, the impulse response functions of the effect of aggregate electricity consumption innovations on the gross domestic product, respectively, are plotted in Figure $1 \mathrm{~b}$. Both the variance decomposition and impulse-response functions reveal that an increase (or decrease) in the total electricity consumption does not affect the gross domestic product. However, the changes in gross domestic product significantly affect the total electricity consumption. As shown in Figure 1a, a positive innovation of gross domestic product has not increased the total electricity consumption. Therefore, savings in electricity consumption will not affect economic growth negatively. 
The variance decomposition of gross domestic product and sub-components of the electricity consumption are given in Table 2. Industrial electricity consumption, the residential-commercial, government offices and street illuminations energy consumption shocks, respectively, come out at $0.15 \% 2.94 \%, 0.13 \%$ and $0.01 \%$ of real gross domestic product forecast error variance. On the other hand, real gross domestic product innovations explain, in turn, the $11.62 \%, 37.35 \%, 25.11 \%$ and $27.03 \%$ of industrial electricity consumption, the residential-commercial, government offices and street illuminations energy consumption forecast error variances.

The response of total electricity consumption and sub-components of electricity consumption to real gross domestic product innovations is eliminated in six periods. On the other hand, the increase in real gross domestic product does affect significantly the total electricity consumption and the sub-components of the electricity consumption. The impulse-response functions of the sub-components of electricity consumption and real gross domestic product are given in Figures 2a,b-5a,b. The industrial, the residential-commercial, government offices and street illuminations electricity energy consumption considerably reacts to real gross domestic shocks and the reaction virtually disappears in six horizons. However, real gross domestic product does not react to the industrial, the residential-commercial, government offices and street illuminations electricity energy consumptionn.

\section{Conclusion}

Unlike most of the studies done in the context of the energy-economics literature, in this paper the relationship between aggregate electricity consumption, its sub-components and real gross domestic product is analysed by means of a structural VAR model. In this context, the impulse- response functions of aggregate electricity consumption, the industrial electricity consumption, the residential-commercial, government offices, and street illuminations energy consumption, real gross domestic product series and structural factorization of the series show that the fluctuations of aggregate electricity consumption, the industrial electricity consumption, the residential-commercial, government offices, and street illuminations energy consumptions have been demonstrated with real domestic gross product shocks. However, aggregate electricity consumption, the industrial electricity consumption, the residential-commercial, government offices, and street illuminations energy consumption innovations have not affected the real domestic product significantly. So, the conservation hypothesis has explained the relevance between aggregate electricity consumption, industrial electricity consumption, the residential-commercial, government offices, and street illuminations energy consumption and real gross domestic product. Thus, gross domestic product shocks lead to fluctuations in electricity consumption. The most important result of this study is that the relationship between industrial electricity consumption and economic growth is extremely weak. It implies that the use of imported energy such as petroleum, coal and natural gas rather than the use of electrical energy produced by all the national resources is increasing relatively in industrial production.

The findings of this study do not overlap completely the results of some studies to investigate the relationship between growth and energy for Turkey's economy. This difference is due to three reasons. First, the periods of analyses are different. Second the variables used in these studies are different. Third, in recent years, the share of petroleum, natural gas, and coal in energy consumption has been relatively increased.

\section{References}

Abosedra, S. Baghestani, H. (1989). New Evidence On The Causal Relationship Between U.S. Energy Consumption And Gross National Product. Journal of Energy and Development. 14(2), 285-292.

Akinlo, A.E. (2008). Energy Consumption and Economic Growth: Evidence from 11 Sub-Sahara African Countries. Energy Economics. 30(5), 2391-2400, doi:10.1016/j.eneco.2008.01.008, http://dx.doi.org/10.1016/j.eneco.2008.01.008

Amisano, G. Giannini, C. (1997). Topics in structural VAR econometrics. (Second edition). Berlin: Springer.

Al-Iriani, M.A. (2006). Energy- GDP Relationship Revisited: An Example GCC Countries Panel Causality. Energy Economics. 34(17), 3342-3350, doi:10.1016/j.enpol.2005.07.005, http://dx.doi.org/10.1016/j.enpol.2005.07.005

Aperdis, N. Payne, J.E. (2009). Energy Consumption and Economic Growth: Evidence from the Commonwealth of Independent $\quad$ States. 31(5), 641-647, doi:10.1016/j.eneco.2009.01.011, http://dx.doi.org/10.1016/j.eneco.2009.01.011

Bernanke, B.S. (1986). Alternative Correlations of The money-Income Correlations. Carnegie- Rochester Conference Series on Public Policy. 25(1), 49-100. http://www.nber.org/papers/w1842.pdf

Blanchard, O.J. and Quah, D. (1989). The Dynamic Effects of Aggregate Demand and Supply Disturbances. The American Economic Review. 79(4), 655-673. 
Cheng, B.S. (1997). Energy Consumption and Economic Growth in Brazil, Mexico and Venezuela: A time Series Analysis. Applied Economics Letters. 4(11), 671-674.

Cheng, B.S. Lai, T.W. (1997). An investigation of Co integration and Causality between energy consumption and economic Activity in Taiwan. Energy Economics. 19(4), 435-444, doi:10.1016/S0140-9883(97)01023-2, http://dx.doi.org/10.1016/S0140-9883(97)01023-2

Erdal, G. Erdal, H. Esengün, K. (2008). The Causality Between Energy Consumption and Economic Growth in Turkey. Energy policy. 36(10), 3838-3842, doi:10.1016/j.enpol.2008.07.012, http://dx.doi.org/10.1016/j.enpol.2008.07.012

Ghosh, S. (2002). Electricity Consumption and Economic Growth in India. Energy Policy 30(2), 125-129, doi:10.1016/S0301-4215(01)00078-7, http://dx.doi.org/10.1016/S0301-4215(01)00078-7

Hatemi-J, A. Irandoust, M. (2005). Energy Consumption and Economic Growth in Sweden, A Leveraged Bootstrap approach 1965-2000. International Journal of Applied econometrics and Quantitative Studies. 2(4), 87-98.

Hondroyiannis, G. Sarantis, L. Papapetrau, E. (2002). Energy Consumption and Economic Growth: Assessing the Evidence from Greece. Energy Economics. 24(4), 319-336, doi:10.1016/S0140-9883(02)00006-3 http://dx.doi.org/10.1016/S0140-9883(02)00006-3

Lee, C.C. (2005). Energy Consumption and GDP in Developing Countries: A Co integrated Panel Analysis. Energy Economics. 27(3), 415-427, doi:10.1016/j.eneco.2005.03.003, http://dx.doi.org/10.1016/j.eneco.2005.03.003

Mozumder, P. Marathe, A. (2007). Causality Relationship between Electricity Consumption and GDP in Bangladesh. Energy Policy. 35(1), 395-402, doi:10.1016/j.enpol.2005.11.033, http://dx.doi.org/10.1016/j.enpol.2005.11.033

Narayan, P.K. Narayan, S. Prasad, A. (2008). A Structural VAR Analysis of Electricity Consumption and real GDP: Evidence from The G7 countries. Energy Policy. 36(7), 2765-2769, doi:10.1016/j.enpol.2008.02.027, http://dx.doi.org/10.1016/j.enpol.2008.02.027

Narayan, P.K. Singh, B. (2007). Electricity Consumption and GDP nexus for Fiji Islands. Energy Economics. 29 (6), 1141-1150, doi:10.1016/j.eneco.2006.05.018, http://dx.doi.org/10.1016/j.eneco.2006.05.018

Narayan, P.K. Smyth, R. (2008). Energy Consumption and Real GDP in G7 Countries: New Evidence from Panel Co integration with Structural Breaks. Energy Economics. 30(5), 2331-2341, doi:10.1016/j.eneco.2007.10.006, http://dx.doi.org/10.1016/j.eneco.2007.10.006

Odhiambo, N.M. (2009). Energy Consumption and Economic Growth Nexus in Tanzania: An ARDL Bound Testing Approach. Energy Economics. 37(2), 617-622, doi:10.1016/j.enpol.2008.09.077, http://dx.doi.org/10.1016/j.enpol.2008.09.077

Paul, S. Bhattacharya, R. N. (2004). Causality between Energy Consumption and Economic Growth in India: A Note on Conflicting Results. Energy Economics. 24(6), 997-983, doi:10.1016/j.eneco.2004.07.002, http://dx.doi.org/doi:10.1016/j.eneco.2004.07.002

Shiu, A. Lam, P.L. (2004). Electricity Consumption and Economic Growth in China. Energy Policy. 32(1), 47-54, doi:10.1016/S0301-4215(02)00250-1, http://dx.doi.org/10.1016/S0301-4215(02)00250-1

Sims, C.A. (1986). Are Forecasting Models Usable for Policy Analysis. Federal Reserve Bank of Minapolis Quarterly Review. (winter), 2-16. http://www.minneapolisfed.org/research/QR/QR1011.pdf

Squalli, J. (2007). Electricity Consumption and Economic Growth: Bounds and Causality Analysis of OPEC Countries. Energy Economics. 29(6), 1192-1205, doi:10.1016/j.eneco.2006.10.001, http://dx.doi.org/10.1016/j.eneco.2006.10.001

Yang, H. Y. (2000). A Note on The Causal Relationship Between Energy and GDP In Taiwan. Energy Economics. 22(3), 309-317, doi:10.1016/S0140-9883(99)00044-4, http://dx.doi.org/10.1016/S0140-9883(99)00044-4 


\section{Appendix}

Table 1.Structural Factorization of GDP and AEC

\begin{tabular}{|l|l|l|l|}
\hline \multicolumn{2}{|c|}{} & \multicolumn{2}{c|}{ Innovations } \\
\hline Var.Dec. & Periods & GDP & AEC \\
\hline GDP & 1 & 99.72 & 0.28 \\
& 5 & 91.29 & 8.71 \\
& 10 & 91.27 & 8.73 \\
& mean & 92.52 & 7.48 \\
\hline Var.Dec. & Periods & GDP & AEC \\
\hline AEC & 1 & 49.53 & 50.47 \\
& 5 & 43.39 & 56.61 \\
& 10 & 43.39 & 56.61 \\
& mean & 43.95 & 56.05 \\
\hline
\end{tabular}

Table 2. Structural Factorization of GDP and Sub-Components of The Electricity Consumption

\begin{tabular}{|c|c|c|c|c|c|c|}
\hline \multirow[b]{2}{*}{ Var.Dec. } & \multirow[b]{2}{*}{ Periods } & \multicolumn{5}{|c|}{ Innovations } \\
\hline & & \multicolumn{2}{|c|}{$\begin{array}{l}\text { GDP } \\
\text { RCEC }\end{array}$} & \multicolumn{2}{|c|}{$\begin{array}{l}\text { IEC } \\
\text { SLEC }\end{array}$} & AUEC \\
\hline \multirow[t]{2}{*}{ GDP } & $\begin{array}{l}1 \\
5 \\
10 \\
\text { mean } \\
\end{array}$ & $\begin{array}{l}99,67 \\
96,19 \\
96,18 \\
96,77 \\
\end{array}$ & $\begin{array}{l}0,07 \\
0,16 \\
0,17 \\
0,15 \\
\end{array}$ & $\begin{array}{l}0,02 \\
0,15 \\
0,16 \\
0,13 \\
\end{array}$ & $\begin{array}{l}0,24 \\
3,48 \\
3,48 \\
2,94 \\
\end{array}$ & $\begin{array}{l}0,00 \\
0,01 \\
0,01 \\
0,01 \\
\end{array}$ \\
\hline & & \multicolumn{2}{|l|}{$\begin{array}{l}\text { GDP } \\
\text { RCEC }\end{array}$} & \multicolumn{2}{|c|}{$\begin{array}{l}\text { IEC } \\
\text { SLEC }\end{array}$} & AUEC \\
\hline \multirow[t]{2}{*}{ IEC } & $\begin{array}{l}1 \\
5 \\
10 \\
\text { Mean }\end{array}$ & $\begin{array}{l}14,35 \\
11,70 \\
11,65 \\
11,62 \\
\end{array}$ & $\begin{array}{l}39,36 \\
28,30 \\
27,97 \\
30,16 \\
\end{array}$ & $\begin{array}{l}2,37 \\
7,67 \\
8,26 \\
7,24 \\
\end{array}$ & $\begin{array}{l}43,89 \\
50,98 \\
50,66 \\
49,79 \\
\end{array}$ & $\begin{array}{l}0,02 \\
1,36 \\
1,46 \\
1,20 \\
\end{array}$ \\
\hline & & \multicolumn{2}{|l|}{$\begin{array}{l}\text { GDP } \\
\text { RCEC }\end{array}$} & \multicolumn{2}{|c|}{$\begin{array}{l}\text { IEC } \\
\text { SLEC }\end{array}$} & AUEC \\
\hline \multirow[t]{2}{*}{ AUEC } & $\begin{array}{l}1 \\
5 \\
10 \\
\text { Mean }\end{array}$ & $\begin{array}{l}0,50 \\
28,28 \\
28,67 \\
25,11 \\
\end{array}$ & $\begin{array}{l}0,50 \\
28,28 \\
28,67 \\
25,11 \\
\end{array}$ & $\begin{array}{l}93,76 \\
65,84 \\
65,45 \\
69,07 \\
\end{array}$ & $\begin{array}{l}0,83 \\
1,09 \\
1,07 \\
1,02 \\
\end{array}$ & $\begin{array}{l}4,82 \\
4,70 \\
4,72 \\
4,72 \\
\end{array}$ \\
\hline & & \multicolumn{2}{|l|}{$\begin{array}{l}\text { GDP } \\
\text { RCEC }\end{array}$} & \multicolumn{2}{|c|}{$\begin{array}{l}\text { IEC } \\
\text { SLEC }\end{array}$} & AUEC \\
\hline \multirow[t]{2}{*}{ RCEC } & $\begin{array}{l}1 \\
5 \\
10 \\
\text { Mean }\end{array}$ & $\begin{array}{l}23,48 \\
39,47 \\
39,49 \\
37,35 \\
\end{array}$ & $\begin{array}{l}0,04 \\
0,20 \\
0,20 \\
0,18 \\
\end{array}$ & $\begin{array}{l}0,59 \\
1,73 \\
1,78 \\
1,50 \\
\end{array}$ & $\begin{array}{l}75,82 \\
58,42 \\
58,35 \\
60,82 \\
\end{array}$ & $\begin{array}{l}0,07 \\
0,17 \\
0,18 \\
0,15 \\
\end{array}$ \\
\hline & & \multicolumn{2}{|l|}{$\begin{array}{l}\text { GDP } \\
\text { RCEC }\end{array}$} & \multicolumn{2}{|c|}{$\begin{array}{l}\text { IEC } \\
\text { SLEC }\end{array}$} & \\
\hline SLEC & $\begin{array}{l}1 \\
5 \\
10 \\
\text { mean }\end{array}$ & $\begin{array}{l}1,98 \\
31,25 \\
31,08 \\
27,03\end{array}$ & $\begin{array}{l}0,01 \\
2,53 \\
2,54 \\
2,17\end{array}$ & $\begin{array}{l}28,27 \\
29,33 \\
29,29 \\
30,23\end{array}$ & $\begin{array}{l}8,90 \\
13,31 \\
13,75 \\
12,74\end{array}$ & $\begin{array}{l}60,84 \\
23,58 \\
23,35 \\
27,84\end{array}$ \\
\hline
\end{tabular}


Figure 1a.Response of AEC to GDP

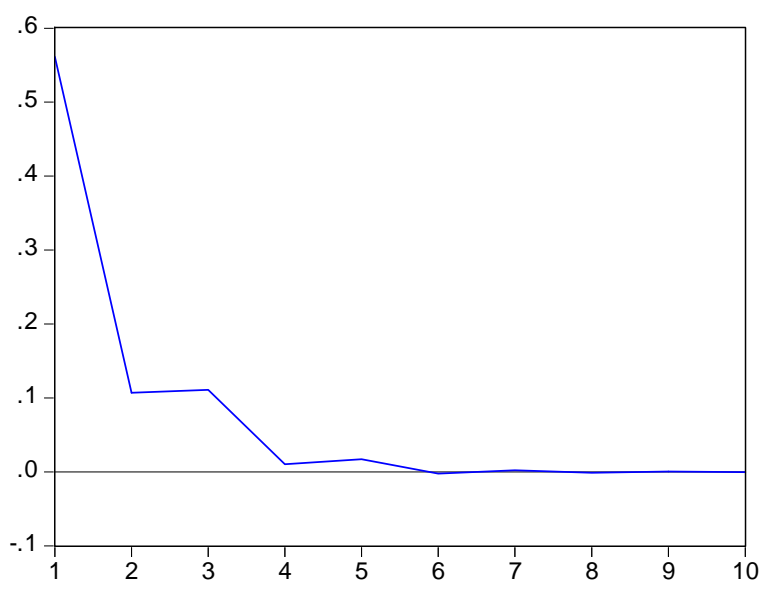

Figure 2a. Response of IEC to GDP

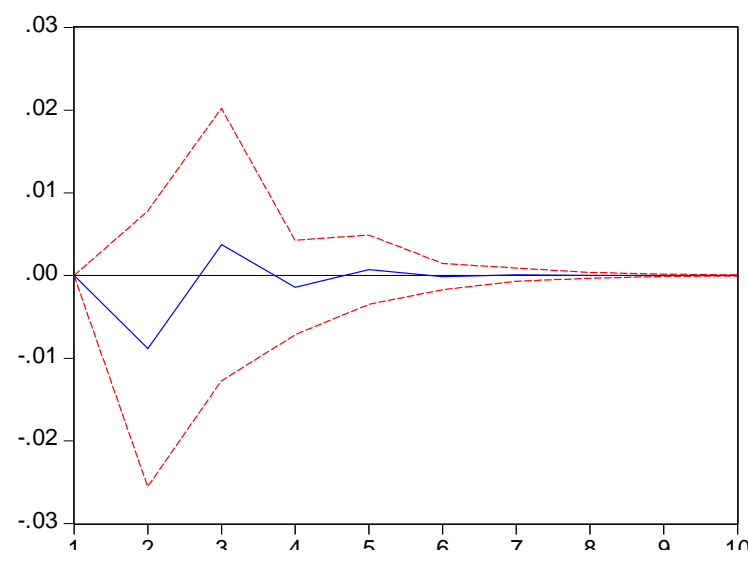

Figure 3a. Response of RCEC to GDP

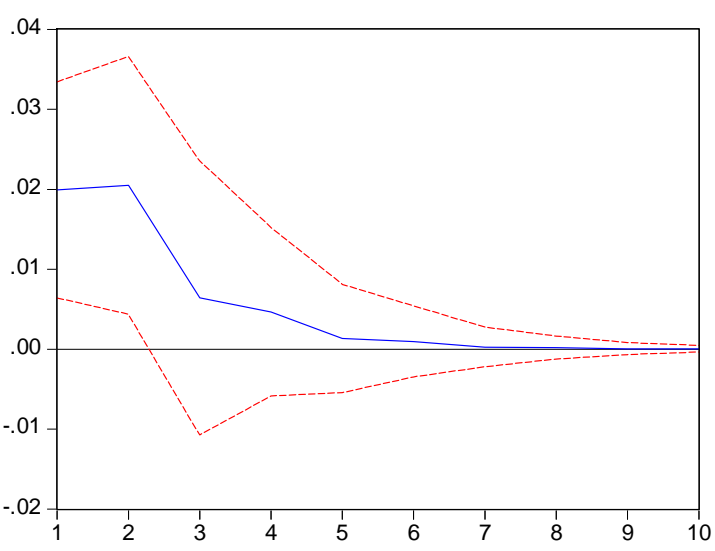

Figure 1b. Response of GDP to AEC

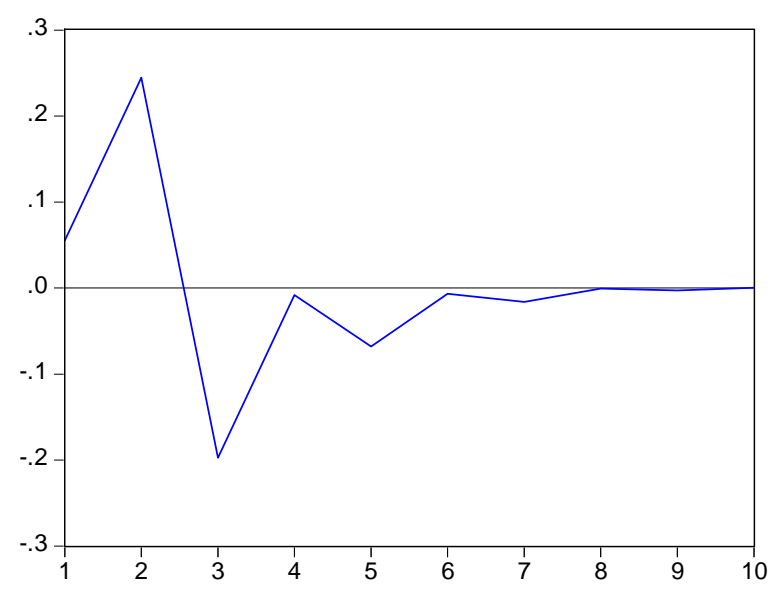

Figure 2b. Response of GDP to IEC

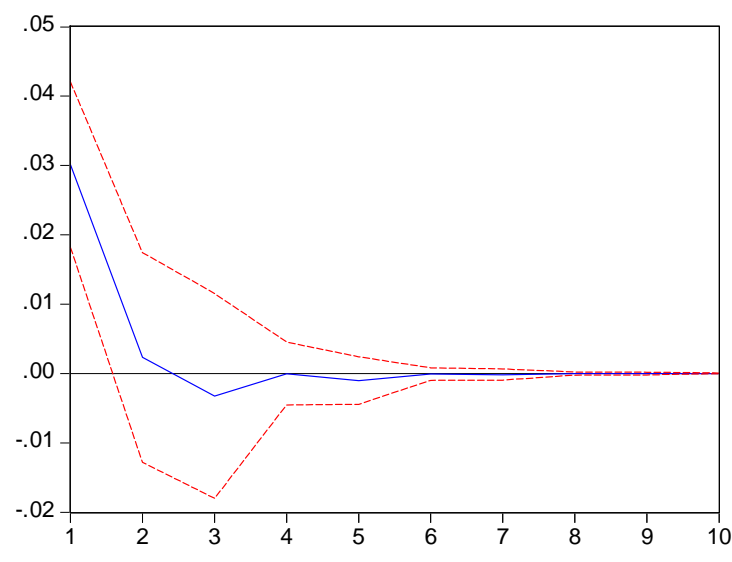

Figure 3b. Response of GDP to RCEC

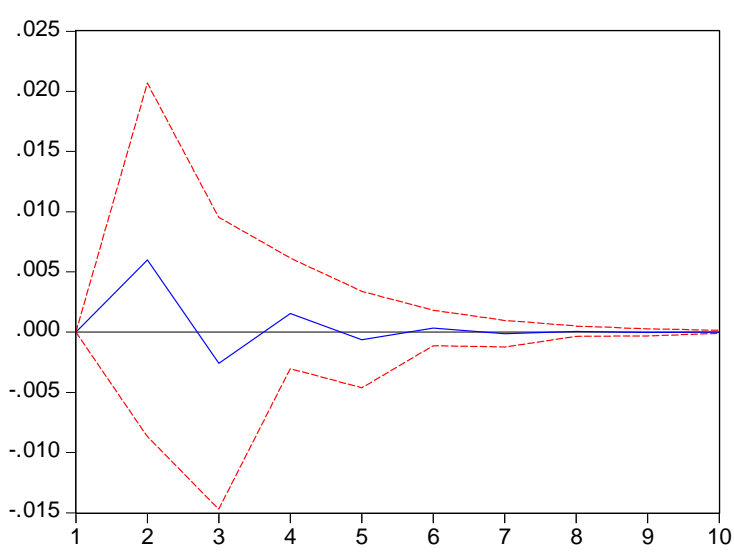


Figure 4a. Response of AUEC to GDP

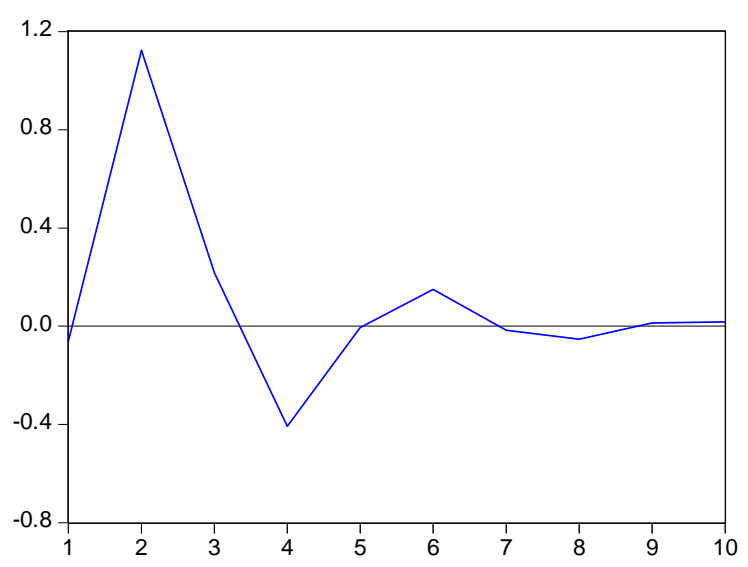

Figure 5a. Response of SLEC to GDP

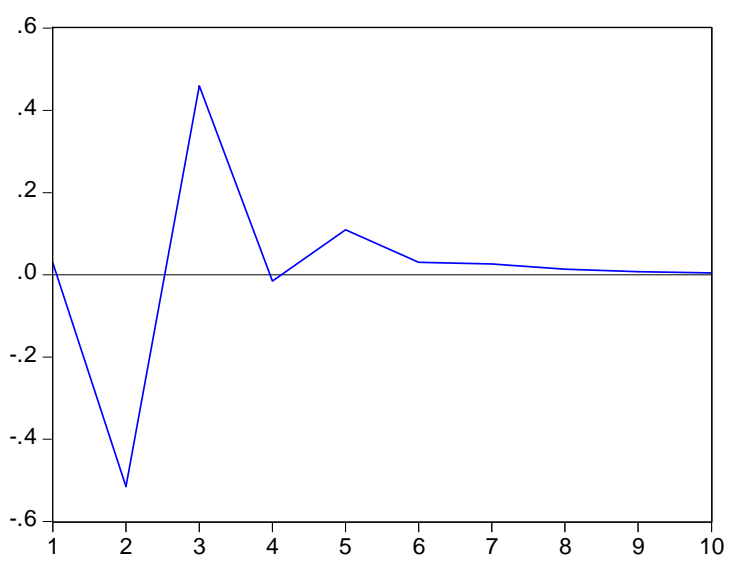

Figure 4b. Response of GDP to AUEC

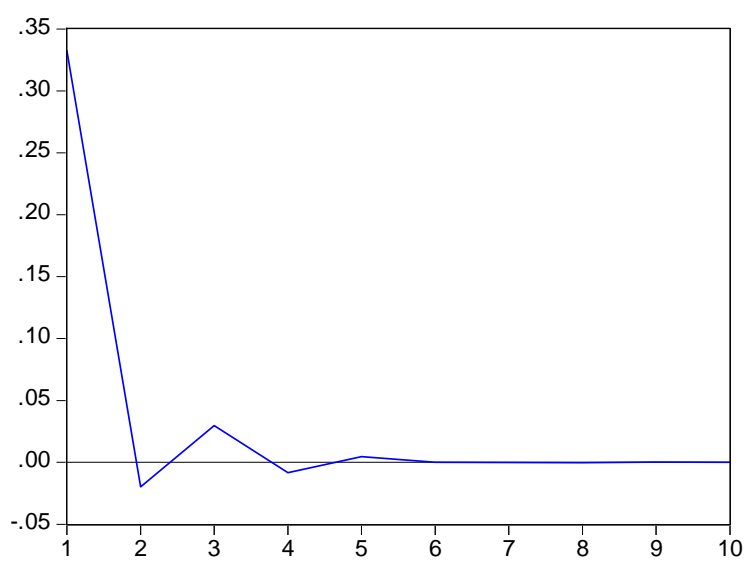

Figure 5b. Response of GDP to SLEC

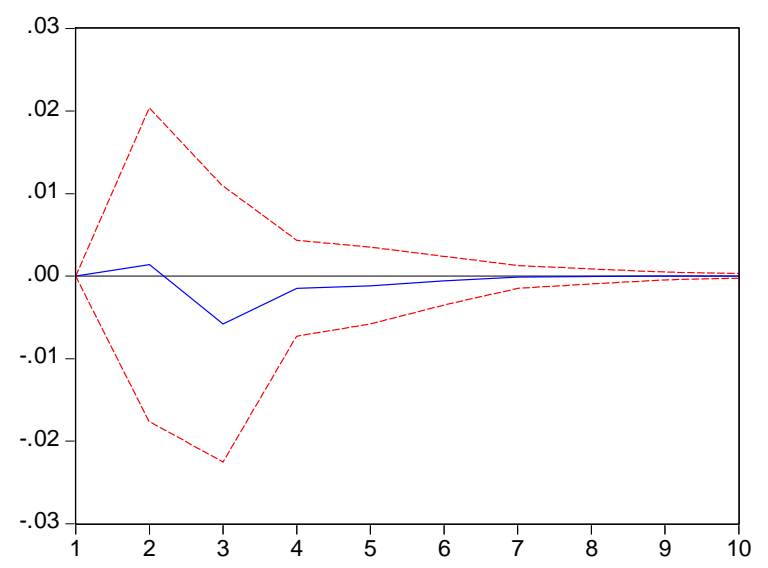

